\title{
Sofia: narrativa de uma história de abandono e sequestro dos direitos de vir a ser
}

Sofia: narrative of a history of abandonment and abduction of the rights to become

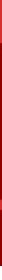

Adriana de Oliveira Lanza Moreira Orsine

Assistente social, Mestre em Promoção da Saúde. Prefeitura de Belo Horizonte.

E-mail: alorsine@gmail.com

\section{Kênia Lara da Silva}

Enfermeira, Doutora em Enfermagem. Universidade Federal de Minas Gerais.

E-mail: kenialara17@gmail.com

\section{Alzira de Oliveira Jorge}

Médica, Doutora em Saúde Coletiva. Universidade Federal de Minas Gerais

Email: alzira.o.jorge@gmail.com

\section{Maria Odete Pereira}

Enfermeira, Doutora em Enfermagem. Universidade Federal de Minas Gerais.

Email:m.odetepereira@gmail.com

\section{Resumo}

Objetivo: Trata-se do relato da trajetória de Sofia que teve suas filhas gêmeas adotadas compulsoriamente. Analisa-se seu percurso nas redes do Sistema Único de Assistência Social em Belo Horizonte, MG, discutindo como o julgamento e os estereótipos criados nesta trajetória definiram a adoção. Métodos: Pesquisa qualitativa, do tipo interferência, delineado como estudo de caso, definido a partir da experiência e percurso de uma usuária-guia. Resultados: O percurso de Sofia nos múltiplos pontos da rede foi atravessado por estabelecimento de vínculos, demandas, ofertas e desejos. $\mathrm{O}$ fato de ser mulher, negra, pobre, usuária de drogas, ter trajetória de rua, vínculos fragilizados ou rompidos, parece ter contribuído na construção de falas relativas às incapacidades e estereótipos acerca de Sofia. Conclusão: $A$ adoção compulsória foi resultado de um complexo processo que envolveu julgamentos sobre Sofia, sem considerar seus desejos, demandas e necessidades. As redes existentes foram limitadas para captar e apreender toda a amplitude e pluralidade das demandas apresentadas e para operar na produção do cuidado. Assim, os direitos de vir a ser de Sofia foram sequestrados com a adoção de suas filhas.

Palavras-chave: Pessoas em Situação de Rua; Assistência Social; Apoio Social; Adoção.

\section{Abstract}

Objective: This is the story of Sofia's trajectory that had her twin daughters adopted compulsorily. Its 
course is analyzed in the networks of the Unique System of Social Assistance in Belo Horizonte, MG, discussing how the judgment and the stereotypes created in this trajectory defined the adoption. Methods: Qualitative research, of the interference type, delineated as a case study, defined from the experience and path of a user-guide. Results: Sofia's journey in the multiple points of the network was crossed by establishing links, demands, offers and wishes. The fact that she is a woman, a black woman, a poor woman, a drug user, a street trajectory, frail or broken ties, seems to have contributed to the construction of statements

\section{Introdução}

Em 2015, aproximadamente 250 milhões de pessoas no mundo usavam drogas, dentre as quais, cerca de 29,5 milhões de pessoas, ou seja, $0,6 \%$ da população adulta global, as consumiam de forma prejudicial, incluindo dependência, com associação de transtornos psíquicos relacionados a esse uso. ${ }^{1}$

No Brasil, o uso abusivo de drogas é crescente, haja vista que o País ocupa o segundo lugar no ranking mundial de consumo de cocaína e o primeiro lugar em uso de crack, além do uso de álcool, que, em 2016, foi de 8,9 litros per capita, superando a média internacional, de 6,4 litros por pessoa., $^{1,2}$

O uso abusivo de drogas e pessoas em situação de rua, são fenômenos comuns às sociedades capitalistas, e onde as desigualdades sociais fazem com que a linha abissal das classes dominantes se contraia e lance para a invisibilidade marginal, os humanos que não correspondem à ideologia produtivista. about the incapacities and stereotypes about Sofia. Conclusion: Compulsory adoption was the result of a complex process involving judgments about Sofia, without regard to her wishes, demands and needs. The existing networks were limited to capture and apprehend the full breadth and plurality of the demands presented and to operate in the production of care. Thus, the rights to become Sophie's were kidnapped with the adoption of their daughters.

Keywords: Street People; Social assistance; Social support; Adoption.

Desta forma, pessoas em situação de rua encontram inúmeras barreiras para acessar ações e serviços públicos e demandam a proteção social do Estado. Nestas circunstâncias, o papel do Estado deve se direcionar para o fortalecimento destas pessoas, agindo a partir de suas necessidades e desejos.

Contudo, assistimos a relatos de frequentes violações dos direitos de um conjunto de cidadãos. Especificamente, esta é a realidade de muitas mulheres em situação de rua e/ou consideradas vulneráveis que têm perdido o direito à maternagem. Sobre elas, pesa um julgamento de que vivem em condições/circunstâncias nas quais a gravidez é um evento "indesejado" na perspectiva de muitos profissionais/serviços que acessam ou percorrem. Pesa, ainda, sobre elas o estereótipo de que são incapazes de gerir a própria vida - pelo uso do crack, pelas precárias, vulneráveis e até "perigosas" condições de vida - conformando, assim, um discurso operante 
sobre estas mulheres e sua impossibilidade de permanecerem com seus filhos.

Este é o enredo da história de Sofia, uma dentre tantas outras atravessadas pelo uso do crack e outras drogas e o direito de vir a ser mãe.

\section{Metodologia}

Este estudo é um subprojeto da pesquisa intitulada: "Rede de Avaliação Compartilhada (RAC), do Observatório Nacional da Produção de Cuidado em Diferentes Modalidades à Luz do Processo de Implantação das Redes Temáticas de Atenção à Saúde no Sistema Único de Saúde: avalia quem pede, quem faz e quem usa".

No decorrer da investigação em Belo Horizonte, Minas Gerais, foram definidos territórios interessados em participar da pesquisa e a designação e acompanhamento de alguns casos, denominados como usuários-guia. Estes foram escolhidos por demandarem abordagem interdisciplinar e intersetorial devido à sua complexidade. Foram eleitos casos de usuários que transitavam há muito tempo nas redes, com exigência de cuidados especiais e constantes, por apresentarem situação de risco e vulnerabilidade pessoal, familiar e social, dentre outras questões. Um destes casos foi de Sofia.

Este texto retrata uma síntese da investigação que foi produzida, tendo como eixo central a "Promoção de saúde e produção do cuidado nas redes do Sistema Único de Assistência Social em Belo Horizonte (SUAS-BH)".
Este trabalho se propôs a analisar a promoção da saúde e a produção do cuidado na gestão das redes de atenção, apoio e proteção do SUAS$\mathrm{BH}$, compreendendo a percepção e atuação de diversos e diferentes atores envolvidos no processo. Especificamente, procurou-se descrever o percurso de uma usuária-guia no acesso e prestação dos serviços socioassistenciais do SUAS-BH, bem como na articulação, mobilização e estabelecimento de redes assistenciais e existenciais; analisar percepções e concepções dos atores envolvidos no estudo, quanto à promoção da saúde e a produção do cuidado relacionadas à prática de ações intersetoriais.

O estudo se caracteriza como pesquisa qualitativa, do tipo interferência, delineado como estudo de um caso, definido a partir da experiência e percurso da usuária-guia.

Foram adotadas as seguintes estratégias e técnicas de pesquisa: coleta, tratamento e análise de dados relativos à trajetória de uma usuária-guia na rede do SUAS-BH, por meio das narrativas da sua história, obtidas nos encontros, atendimentos, visitas, conversas, entrevistas com trabalhadores que atenderam a usuária, bem como com a mesma. Foi utilizada também a técnica de análise documental para consultar registros de prontuários, fichas de atendimentos ou outros documentos que auxiliassem na construção da narrativa.

No total, foram entrevistados 11 profissionais, lotados nos equipamentos da Assistência 
Social: Abrigo; Centro de Referencia da Assistência Social; Gerencial Regional; República; Equipe de Atendimento à população em Situação de rua. Esses participantes foram considerados atores-chaves, identificados intencionalmente e evidenciados como tendo papel de destaque e relevância no processo de gestão, articulação e produção do cuidado à usuária. Os participantes foram esclarecidos sobre os aspectos éticos relativos à pesquisa com seres humanos e assinaram o Termo de Consentimento, atendendo às exigências da Resolução 466/2012. A pesquisa foi aprovada por Comitê de Ética em Pesquisa da Secretaria Municipal de Saúde de Belo Horizonte.

Os dados foram analisados por meio de categorias que envolveram vínculo; acesso; adesão; oferta; demanda e desejo, atrelados ao papel das políticas públicas, à definição e cumprimento de protocolos; à atuação do profissional na produção do cuidado a Sofia.

Afinal, quem é Sofia? Esta e outras mulheres com histórias marcadas pela vulnerabilidade e pela adoção compulsória

Sofia, 34 anos, proveniente de São Paulo, migrou para $\mathrm{BH}$ em virtude da dependência do crack, que faz uso desde a infância e da ruptura dos vínculos familiares, que teve oportunidades de restabelecer, mas não quis retomar a convivência. Tem trajetória de vida nas ruas, sem fixação definida, sempre morando em locais precários e insalubres.
Desde 2008 é companheira do Senhor T, um carroceiro de 61 anos, com trajetória de vida nas ruas, dependência química, considerado pelos profissionais de saúde e assistência social como tendo comportamento arredio e de difícil aproximação e estabelecimento de vínculos, além de manifestar conflituosa relação com Sofia. Aliás, os relatos dos profissionais a respeito da falta de implicação e adesão do casal à maioria dos encaminhamentos na área da saúde e da assistência social foram constantes.

Registros do seu percurso na rede da Política de Assistência Social relatavam que, desde 2004, ela acessou vários serviços, programas, unidades de atendimento e benefícios sócioassistenciais do SUAS-BH, vinculados à Proteção Social Básica e Especial, de Média e Alta Complexidades, como rede de proteção e apoio.

Quanto aos cuidados com a saúde, que sempre foi frágil, Sofia era considerada negligente. Chegou a ser internada para tratamento de tuberculose, mas abandonou, fugindo do hospital. Só procurava assistência médica quando se sentia muito mal, recorrendo aos serviços de urgência, na maioria das vezes.

$\mathrm{Na}$ defesa e garantia de direitos, acessou a Defensoria Pública, Vara da Infância e Juventude da Comarca de Belo Horizonte, Conselho Tutelar e outros. Foi encaminhada para uma Cooperativa Solidária de Trabalhadores, dentre outras ações voltadas para a promoção social. 
Teve cinco gestações, sendo que uma resultou em aborto. Dos filhos, dois moravam em São Paulo com a avó materna e outro, com quem afirmava manter vínculos, estava com a madrinha, em uma cidade do interior de Minas Gerais. A última gestação foi em 2014, de gêmeas, tendo sido de alto risco e sem a realização do pré-natal. Considerava a gravidez como uma oportunidade para mudar de vida, no entanto, após o nascimento, as recémnascidas foram acolhidas em abrigo, por aplicação de medida judicial protetiva e, logo em seguida, "adotadas compulsoriamente".

A adoção compulsória é apenas um capítulo da vida de Sofia, mas esse poderia ter sido construído de outra maneira se sua trajetória no percurso das políticas sociais tivesse tido outro desfecho.

A trajetória de Sofia e a construção de redes: desafios da proteção social

O cuidado como dispositivo de proteção social foi produzido junto a Sofia pelas seguranças da assistência social, operacionalizadas na oferta dos serviços, programas, projetos e benefícios sócio-assistenciais, bem como nas aquisições pessoais e sociais advindas do cotidiano das relações, interações e conexões estabelecidas nas redes do SUAS-BH.

A adesão de Sofia teve relação com o vínculo firmado e com a sua assimilação/identificação com as ofertas. Em alguns serviços, chegou a aderir, estabelecendo vinculações mais intensas, duradouras e produtivas. Em outros, constituiu afinidades menos consistentes, com demandas para atendimentos pontuais e emergenciais. Houve, ainda, aqueles em que ela foi apenas referenciada e/ou cadastrada como caso, gerando somente a identificação de um número de prontuário, sem a consolidação de relações férteis e vigorosas.

Ainda com relação à adesão, os dados demonstraram a existência de obstáculos remetidos para o âmbito do sujeito, numa lógica voltada para a capacidade específica do usuário de dar conta e se implicar nas intervenções e da responsabilidade por adquirir e qualificar a aquisição de ofertas recebidas. Nesse sentido, foi atribuída a Sofia a responsabilidade particular em aderir e se implicar no alcance e qualidade da promoção das ofertas.

"Acredito que as ações eram realizadas para que conseguisse autonomia, mas, às vezes gerava sua dependência e até tutela do serviço. Mas Sofia era muito independente com suas questões. (...) 0 uso da droga é forte e dificulta a sua autonomia. Além disso, o trabalho com ela era diferente e mais complicado, com muitos desafios. (...) A organização dela era de acordo com o estado em que estava." (Entrevistado 01).

\footnotetext{
“Quando vem prá cá, a gente quer mudar a pessoa para uma questão melhor. Eu acho que ela aderiu aos encaminhamentos, mas não sei se dentro do intimo dela, se isso era real. É especifico de cada um. (...) Ela estava assimilando o que estava sendo proposto e fazendo movimentos para melhorar. (...) O movimento de promoção é muito mais interno do que externo. (...) Também tem outras questões envolvidas, relacionadas às individualidades e não ao coletivo. (...) Ela se movimentava em busca das coisas que queria e acreditava. Saia para trabalhar, para vender balas no sinal de trânsito. Manifestava preocupação em
} 
buscar uma fonte de renda, uma autonomia para tentar melhorar e mudar de vida. (...) Quando era para falar sobre a sua vida, em algumas situações, ela se esquivava." (Entrevistado 03).

A adesão de Sofia estava atrelada à disponibilidade da oferta e ao fato de conseguir acessar serviços, por meio da adequação e cumprimento das exigências em relação aos protocolos rígidos. Nessas circunstâncias, a adesão de Sofia foi restrita e quando não era do seu interesse, se esquivou de forma espontânea.

De certa forma, o cuidado foi produzido em conformidade com a demanda e adesão da usuária e de acordo com o comprometimento, envolvimento, habilidades e disponibilidade do profissional em se afetar com e pela história da usuária, abrindo brechas e flexibilizando normas, para ampliar as possibilidades de atendimento, como expressou um dos participantes:

"A metodologia, os protocolos, papéis e atribuições podem limitar a produção do cuidado. (...) A expectativa é nossa, quando a pessoa chega a oferta é dada por nós". Está tudo pronto, só falta ela aderir. Tem um protocolo a seguir, que é muito estanque. (...) A gente não dá conta da Sofia. Temos um cardápio recheado e limitado. Fazemos de tudo, mas, ela não adere. (...) Estamos ofertando o que é do desejo dela ou nosso? (...) Nem é questão do nosso desejo, mas do que é colocado pela política. Acho que a trajetória dela vai ser permanente, enquanto tiver serviço disposto a atendê-la e ser direito dela. (Entrevistado 10).

A adesão também foi relacionada ao desejo. Para alguns desejos manifestados pela usuária, tiveram ofertas disponíveis, para outros, não.
Ela manifestou o interesse em tratar o uso de drogas; de participar e produzir nas oficinas; trabalhar com carteira assinada; de poder ficar com as filhas; ter uma moradia; ter direitos assegurados; poder ser ela mesma; de não fazer tratamento contra TBC, dentre outros.

Neste sentido, Sofia era uma pessoa ativa e com anseios. Foi capaz de mobilizar redes, decidir e fazer escolhas. Houve momentos em que Sofia rompeu com os combinados não permitindo ser abordada e desconsiderando naturalmente os acordos. Sempre se esquecia de algo ou não dava a devida importância. Para alguns profissionais, o seu comportamento era inaceitável, frente à apresentação de ofertas irrecusáveis, às quais a usuária só precisava aderir.

\footnotetext{
"Ela dizia: Era hoje, nem lembrei. Achei que era de tarde. (...) Logo ontem, no dia do meu aniversário, fui passear no Parque Municipal, até fiz amizades lá. (...) Ela não era obrigada a participar e, para além do envolvimento espontâneo, demonstrava gostar de estar nas reuniões, assembleias; oficinas; festas; eventos; gincanas; mutirões de limpeza e, manifestava suas opiniões. Ela sempre soube buscar o que queria e sempre se articulava." (Entrevistado 05)
}

\begin{abstract}
"Quando não queria ela escorregava entre os dedos, ia estabelecendo as estratégias dela de não implicação, por uma série de questões e não ficava desprotegida, pois continuávamos a acompanhando de alguma forma. (...) Do que desejava, enquanto cuidado, com certeza estava sendo atendida. (...) Nós esperávamos mais do que isso, ela também tinha que ofertar alguma coisa." (Entrevistado 09).
\end{abstract}

Em algumas circunstâncias, mesmo demonstrando falta de vontade e empenho, a usuária foi levada, pelos profissionais, a acessar serviços, por prescrição e imposição do 
cumprimento da burocracia estabelecida pelo Sistema. Tudo conduzido pelo ponto de vista e assimilação dos profissionais e de acordo com a disponibilidade das ofertas das políticas públicas, sem levar em consideração as vontades da usuária e as particularidades do caso. Por outro lado, Sofia, a seu modo, também conseguiu burlar as normas e protocolos instituídos.

\begin{abstract}
"Ela estava indo ao hospital para amamentar. Até que chegaram a falar que as gêmeas não iriam para ela. (...) O impacto foi aí. Eu achei que ela ia baquear. Deveriam conversar aos poucos e mostrar para ela que era melhor, ia aceitando mais. (...) Com a convivência no serviço, foi se adaptando, da melhor maneira possível e conseguindo se organizar. Aderia às atividades e encaminhamentos que eram propostos para ela como de médico, de documentos e quando tinham oficinas, ela também ia e participava muito consciente do que estava fazendo." (Entrevistado 04).
\end{abstract}

A ideia de não dar conta, na visão dos profissionais, foi moldada e atribuída à usuária, por causa e consequência da sua condição de vulnerabilidade, que originou exclusão e dificuldades para superação das fragilidades.

"A forma como foi conduzido o processo do acolhimento das crianças não foi a mais correta, não foi trabalhada a possibilidade de reintegração familiar e isso, prejudicou muito Sofia. Teve uma ruptura brusca. (...) A profissional confirmou que Sofia não tinha vínculo com as crianças e que ela ia ao hospital apenas para almoçar e, que provavelmente, as meninas seriam adotadas. Já veio com a fala pronta. (...) Nem o Abrigo ficou sabendo sobre o acolhimento das gêmeas e, posteriormente, fomos informados da adoção. (...) Na ocasião da internação das filhas, ela aderiu a vários encaminhamentos, na tentativa de poder ficar com elas, mas não foi dada a oportunidade. (...) Mesmo comparecendo à Defensoria Pública e à
Vara da Infância e Juventude, não obteve informações sobre as filhas e nunca mais pode vê-las. (...) Quando ia ao hospital, dizia ter medo de pegar as meninas no colo e passar alguma doença para elas, por conta da sua história e convivência com a rua. (...) Sofia contestava a fala da profissional do hospital, com relação a sua ida, apenas para comer. Dizia que não precisava disso, por ter comida no Abrigo e, que quando ia visitar as filhas, sabia não ser bem quista." (Entrevistado 11).

O dar ou não conta atribuiu à usuária uma aptidão específica de ser capaz ou não; enquanto a circunstância de estar preparada ou não, conferiu a mesma a possibilidade de se organizar e se qualificar para conseguir dar conta, levando em consideração limitações e dificuldades que podiam ser trabalhadas e sanadas.

O fato de ser mulher, negra, pobre, usuária de drogas, ter trajetória de rua, vínculos fragilizados ou rompidos, dificuldade de exercer a maternagem, dentre outras questões, parece ter contribuído e até determinado a construção de falas relativas às incapacidades de Sofia. Ademais, contribuíram para a construção de um estereótipo acerca dela, o que pode ter provocado à subjugação de Sofia, a partir da produção de imagem induzida e prejudicada, com incapacidades atribuídas e incutidas a ela, por parte dos profissionais. Sofia pode ter sido levada a se sujeitar e incorporar uma condição de submissão, assumindo a representação produzida pelo olhar dos outros e que gerou mudanças de rumos e determinou seu modo de levar a vida.

\footnotetext{
“Na primeira oportunidade que tivesse, iria se
} envolver com as drogas, e seria negligente com as 
meninas. O fato de estar aqui poderia ajudar, mas, mesmo com o apoio, acho que ela não daria conta, por causa das drogas e de ser de rua. (...) Nessas situações é mais difícil lidar e superar certas coisas. O desafio é muito maior. (...) Ela conseguia se manifestar, com clareza, sabia o que queria, mesmo que não desse conta de sustentar ou mudasse de opinião. (...) Quando participava e produzia nas oficinas, mostrava o seu trabalho e dizia: “olha, hoje eu consegui fazer isso. Dá até prá ganhar algum dinheiro!" Ela se sentia animada, importante e demonstrava vontade de mudar. (...) Quanto a mudar de vida, numa perspectiva mais ampla, acho que ela não deu conta de concretizar muitas coisas. (...) Não vamos colocar a responsabilidade só nela, por não ter conseguido se promover, mas também não vamos culpar o serviço. (...) Há algo que é da Sofia, de você ofertar e ela não conseguir. (...) Não adiantaria melhorar nada, porque nesse caso, a questão estava com ela. Por mais que se fizesse de tudo para conseguir a adesão dela, mesmo que ela tivesse vontade, ela não dava conta. (...) Considero que todos os profissionais dos diversos serviços e áreas, interviam e faziam de tudo para conseguir a adesão e envolvimento da Sofia, para que ela pudesse dar conta e ser capaz e, com o objetivo de melhorar a sua condição." (Entrevistado 04).

\footnotetext{
"Tinha vontade de superar a sua condição de vulnerabilidade, de mudar sua história, mas não dava conta, até mesmo pelo uso de drogas, da história de rua e por influência do companheiro. Por mais que tivesse força de vontade, o companheiro estimulava o seu uso de drogas. Ela fazia alguns movimentos, mas, não dava conta. $E$ acho que devido a isso, ela não daria conta de cuidar das filhas." (Entrevistado 03).
}

Esta é a história de Sofia. Sofia que ainda menina foi viver na rua. Que criança escolhe viver nas ruas se tiver uma família que lhe dê segurança e afeto? Entregue à própria sorte, a menina em momento algum recebeu um olhar de cuidado por parte do Estado. No entanto, este mesmo Estado hoje lhe tira as filhas recém-nascidas com a argumentação de que é preciso lhes dar uma família, para que cresçam bem e em segurança. O Estado que abandona é o mesmo que sequestra de Sofia os seus direitos de vir a ser.

A ideologia higienista parece dar o tom às ações desse Estado de exceção. Se a esterilização compulsória já não é mais possível como instrumento de higiene mental, ${ }^{3}$ a retirada do direito à maternagem de mulheres usuárias de drogas em situação de rua, parece ser estratégia mais requintada de mecanismos judiciários, com o mesmo objetivo.

A história de Sofia e de tantas outras é corroborada por estudo realizado em Belo Horizonte, em 2016, com 191 mulheres em situação de rua que destacou a prevalência de mulheres com idades entre 31 a 50 anos, mães solteiras, sendo $18,3 \%$ sem vínculo familiar. Dentre elas, $60 \%$ eram analfabetas ou não haviam completado o ensino fundamental; $40,2 \%$ faziam uso de drogas; $62,7 \%$ tinham problemas familiares. Em 40,3\% dos casos, os conflitos no lar foram desencadeados pelo uso abusivo de álcool; em 37,6\% por desavenças e em $19,7 \%$ devido a vivência de sofrimento mental. ${ }^{4}$

Villa et al. ${ }^{4}$ concluíram que as mulheres em situação de rua merecem a atenção dos gestores na formulação de políticas públicas, com o planejamento de ações em diferentes setores da sociedade que acolham suas demandas.

\section{Considerações finais}

A adoção compulsória foi resultado de um complexo processo que envolveu construção de estereótipos e julgamentos sobre Sofia, sem 
considerar seus desejos, demandas e necessidades. Houve, portanto, baixa capacidade de ofertas e produção de cuidado que gerasse implicações produtivas de um novo olhar sobre essa usuária a partir da sua história e conquistas, e não apenas do que se apresenta a partir do seu ponto de vista ou do olhar dos outros sobre si e suas capacidades de dar ou não conta de ser o que o outro esperava dela.

Neste contexto, para produzir cuidado há a necessidade de romper com os ciclos estabelecidos nos serviços e políticas e fabricar a tessitura da rede de cuidado junto aos usuários, no cotidiano das suas relações, com ofertas que consolidem a potencialidade e perspectivas dos encontros estabelecidos pelas redes quentes e suas conexões existenciais.
As várias narrativas sobre adoção compulsória, como a que aconteceu com Sofia e suas filhas, revelam que, se por um lado, retira-se uma criança de uma mulher negra, pobre, usuária de drogas e em situação de rua, por outro, presenteia-se algum casal brasileiro ou estrangeiro, pertencente a elite, que não pode gerar ou parir seu próprio filho.

As autoras acreditam que poder-se-ia construir um outro desfecho no caso, um desfecho, mesmo que transitório, em que mãe e filhas recebessem do Estado o direito à moradia e o apoio necessário nas suas escolhas, para que Sofia e sua família pudessem construir uma história de inclusão e o direito de vir a ser a "mãe capaz" dentro das suas possibilidades e desejos.

Nota

'Dissertação defendida no Programa de Pós-graduação em Promoção da Saúde e Prevenção da violência da Faculdade de Medicina da UFMG pela autora principal.

\section{Referências}

${ }^{1}$ United Nations Office on Drugs and Crime. World drug report 2015. New York: United Nations; 2015.

${ }^{2}$ International Drug Policy Consortium. The United Nations General Assembly Special Session (UNGAAS) on the world drug problem. Report of proceedings. International Drug Policy Consortium Publication; 2016.

${ }^{3}$ Costa J. A história da psiquiatria no Brasil: um corte ideológico. Rio de Janeiro: Garamond; 2006.

${ }^{4}$ Villa E, Pereira MO, Reinaldo AMS, Neves NAP, Viana SMN. Sociodemographic profile of women in street situation and vulnerability for the use of psychoactive substances. J Nurs UFPE. 2017;11(5):2122-31. 